\title{
O portfólio como estratégia facilitadora do processo de ensino-aprendizagem para a formação em odontologia. Adequação de metodologias de ensino utilizando o ambiente virtual de aprendizagem
}

\author{
Myrna Maria Arcanjo Frota*, Léa Maria Bezerra de Menezes**, Carlos Henrique \\ Alencar***, Lidiane da Silva Jorge****, Maria Eneide Leitão de Almeida**

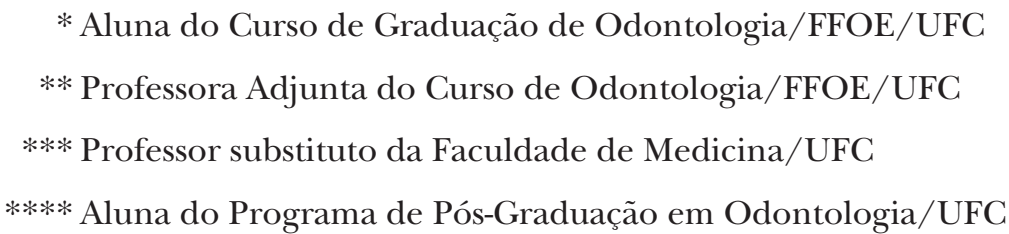

\section{RESUMO}

A busca de conhecimento, a criatividade e a produção escrita são incentivadas quando se utiliza o portfólio como instrumento de aprendizagem. Esse trabalho tem como objetivo avaliar o portfólio como um instrumento facilitador do processo de ensinoaprendizagem para a formação em Odontologia. Trata-se de uma pesquisa descritiva e transversal, realizada no semestre letivo de 2010.2 no Curso de Odontologia/UFC. Foi aplicada aos acadêmicos regularmente matriculados nas disciplinas de Metodologia Científica aplicada a Odontologia I e Saúde Coletiva II, totalizando 60 alunos e aos 03 professores das referidas disciplinas. A coleta de dados foi feita por meio de questionários eletrônicos utilizando-se a lista de email cadastrado no ambiente virtual de aprendizagem. Para análise, as informações obtidas foram organizadas em um banco de dados no Excel e posteriormente, analisados no programa estatístico Epi-info versão 3.5.1. A pesquisa foi submetida à apreciação e aprovada pelo Comitê de Ética em Pesquisa, protocolo $\mathrm{n}^{\circ} 157 / 10$. Analisando os questionários dos alunos, $100 \%$ avaliaram o portfólio como excelente ou bom como método de avaliação; Cerca de 98,3\% dos discentes afirmaram que o portfólio é melhor em termos de aprendizagem que as provas tradicionais; e $100 \%$ dos alunos afirmaram que a metodologia de ensino-aprendizagem utilizando o portfólio facilita o processo de aprendizagem. Todos os professores acre- ditam que é maior o rendimento dos alunos quando é usado o portfólio e que este facilita a aprendizagem. Concluiu-se que a utilização do portfólio é um instrumento pedagógico válido, bem aceito pelos alunos e que pode ser empregado no ensino odontológico.

\section{DESCRITORES}

Ensino. Educação em Odontologia. Avaliação Educacional.

$\mathbf{0}$ Pró-Saúde tem como objetivo geral contribuir para a promoção das políticas de inclusão social e educação permanente em saúde, por meio da reorientação da formação profissional de trabalhadores em saúde bucal e da integração dos processos de geração de conhecimentos, ensino-aprendizagem e prestação de serviços de saúde à população, com foco na atenção básica e ênfase no direito à saúde e no cuidado e proteção à vida.

A adequação das metodologias de ensino, permitindo melhorias no desempenho acadêmico dos alunos e professores, estimulando o processo de educação permanente por meio de seminários e oficinas de capacitação tem sido uma proposta permanente do Projeto Pró-Saúde e especificamente, no projeto proposto pelo Pró-Saúde II que contemplou os cursos de Farmácia, Odontologia e Psicologia da Universidade Federal do Ceará em 2008, que possui como um dos seus objetivos específicos, estimular novas metodolo- 
gias de estudos através de mecanismos interativos de aprendizagem.

Dessa forma, destaca-se o uso dos ambientes virtuais de aprendizagem, pois as tecnologias de informação e comunicação possuem novas maneiras de atuar no ensino, praticando a modalidade do ensino à distância, que contribui para o processo de ensinoaprendizagem e facilita a comunicação entre professores e alunos. Nesse contexto, foi implementado o uso do portfólio educacional como objeto de estudo para os acadêmicos através do ambiente virtual de aprendizagem, o SOLAR desenvolvido em 2002 pelo Instituto UFC Virtual da Universidade Federal do Ceará e utilizado no Curso de Odontologia da Faculdade de Farmácia, Odontologia e Enfermagem (FFOE), inicialmente, a partir de 2009 na disciplina de Saúde Coletiva II $\left(6^{\circ}\right.$ semestre) e em 2010, na disciplina de Metodologia Científica Aplicada a Odontologia I ( $1^{\circ}$ semestre).

A prática de elaboração de portfólio também foi adotada na Universidade de São Paulo. Bim-Junior e Tomita (2008) concluíram que a percepção sobre o processo ensino-aprendizagem mostrou aspectos críticos, éticos e cotidianos da vida acadêmica, sendo o portfólio uma maneira de problematizar diferentes eventos inerentes à formação profissional possibilitando a compreensão que leva ao aprendizado.

Numa pesquisa desenvolvida por Tangi e Dantas da Silva (2008) no Curso de Enfermagem, Rio de Janeiro, cujo objetivo foi demonstrar as potencialidades e dificuldades da utilização do portfólio reflexivo como instrumento de aprendizagem, apontou que um dos maiores dilemas para os estudantes foi a dificuldade mediada pela comunicação escrita quando chamados aos relatos de suas trajetórias de vida tanto pessoais, como nas travessias de aprendizagem ao longo do Curso de Graduação em Enfermagem.

Pode-se entender o portfólio como instrumento facilitador da construção e reconstrução do processo ensino-aprendizagem que permite o aluno refletir sobre a realidade local, identificando os problemas e analisando-os criticamente. A busca de conhecimento, a criatividade e a produção escrita são incentivadas de modo que o aluno deverá trilhar seu próprio conhecimento acompanhado pelo professor que avaliará esse caminhar.

Segundo Hernández (2000), o Portfólio é o continente de diferentes classes de documentos (notas pessoais, experiências de aula, trabalhos pontuais, acompanhamento do processo de aprendizagem, conexões com outros temas fora da escola, representa- ções visuais, dentre outros) que proporciona uma reflexão crítica do conhecimento construído, das estratégias utilizadas, e da disposição de quem o elabora em continuar aprendendo.

Historicamente, esse instrumento vem se constituindo com diversas nomenclaturas que se diferenciam de acordo com suas finalidades e espaços geográficos. Dentre os mais correntes estão: porta-fólios, processo-fólios, diários de bordo e dossiê. Esse instrumento já se apresenta com algumas classificações: portfólio particular, de aprendizagem, demonstrativo e, recentemente, passa-se a incluir o webfólio (Alves, 2006).

O Portfólio é esse instrumento que reflete a trajetória desse saber construído. Também possibilita aos alunos e professores uma compreensão maior do que foi ensinado (Vieira, 2002).

Também é muito utilizado como meio de avaliação, esta concentra a atenção de todos (dos alunos de um mesmo grupo, dos professores e dos orientadores) nos trabalhos importantes dos alunos. O processo estimula o questionamento, a discussão, a suposição, a proposição, a análise e a reflexão. Fazendo com o que os alunos aprendam cada vez mais sobre os assuntos discutidos em sala de aula, e não sejam simples ouvintes do processo e sim, participadores ativos.

Segundo Alvarenga (2001), o Portfólio tem como maior objetivo ajudar o estudante a desenvolver a habilidade de avaliar seu próprio trabalho.

Esse trabalho tem como objetivo avaliar o portfólio como um instrumento facilitador do processo de ensino-aprendizagem para a formação em Odontologia, assim como as facilidades e dificuldades que os alunos enfrentaram na confecção do portfólio; o grau de aceitação do portfólio em relação aos alunos e suas opiniões acerca desde método de ensino; identificar as vantagens do portfólio em relação às provas tradicionais e identificar as vantagens e dificuldades dos professores em avaliar o portfólio.

\section{MATERIAL E MÉTODOS}

Trata-se de uma pesquisa descritiva e transversal, realizada em Fortaleza no semestre letivo de 2010.2 no Curso de Odontologia/FFOE/UFC.

Foi aplicada aos acadêmicos regularmente matriculados nas disciplinas de Metodologia Científica aplicada a Odontologia I e Saúde Coletiva II, totalizando 60 alunos e aos 03 professores das referidas disciplinas ao final do período letivo.

A coleta de dados foi feita por meio de questionários eletrônicos utilizando-se a lista de email cadastra- 
do no ambiente virtual de aprendizagem, portanto, como critério de inclusão dos estudantes e professores, era necessário estar matriculado no SOLAR. Como critério de exclusão dos professores, aqueles que davam aula esporadicamente nas referidas disciplinas e não acompanhavam os alunos no SOLAR, foram excluídos.

Para avaliar a facilidade de compreensão do instrumento como um todo e de cada item isoladamente foi realizado um teste piloto para a validação dos questionários, sendo identificados 03 professores e 10 alunos para realizarem o referido teste. Esse grupo sugeriu modificações, relataram as dificuldades que tiveram, e usaram sinônimos para as palavras com possibilidade maior de incompreensão chegando-se à versão final do questionário.

Para análise estatística, as informações obtidas foram digitadas e organizadas em um banco de dados no Excel e posteriormente, analisados no programa estatístico Epi-info versão 3.5.1 para Windows. As variáveis foram descritas com freqüência absoluta simples e por classe, juntamente com as respectivas freqüências relativas (percentuais) simples e acumulativas.

A pesquisa foi submetida à apreciação e aprovada pelo Comitê de Ética em Pesquisa, protocolo $n^{\circ}$ 157/10. Foi aplicado um Termo de Consentimento Livre e Esclarecido para os alunos e professores.

\section{RESULTADOS}

Analisando os questionários dos alunos, $100 \%$ avaliaram o portfólio como excelente ou bom como método de avaliação.

Dos discentes analisados, $61,7 \%$ afirmaram que tem dificuldade em confeccionar o portfólio.

Cerca de 60,3\% dos alunos afirmam que a maior dificuldade em confeccionar o portfólio foi devido a necessidade de pesquisar artigos científicos e a capacidade de síntese.

Para 98,3\% dos discentes o portfólio é melhor em termos de aprendizagem que as provas tradicionais e $88,3 \%$ se sentem motivados em realizar o portfólio em outras disciplinas.

Quando indagados se sentem seguros para estudarem sozinhos, $46,7 \%$ dos alunos responderam que não se sentem preparados para tal; Um pouco mais da metade dos alunos $(51,7 \%)$ conseguiu realizar as atividades propostas para a confecção do portfólio com facilidade.

A maioria $(93,3 \%)$ dos alunos considerou que o tempo dado para a execução do portfólio foi suficien- te e $100 \%$ dos alunos afirmaram que a metodologia de ensino-aprendizagem utilizando o portfólio facilita o processo de aprendizagem.

Dos professores analisados, dois destes são professores de Saúde Coletiva II e um de Metodologia Científica aplicada à Odontologia I.

Todos os professores acreditam que é maior o rendimento dos alunos quando é usado o portfólio e que este facilita a aprendizagem tanto individual como do grupo.

Os professores analisados consideram que o tempo dado para a execução do portfólio foi suficiente e todos eles não tiveram dificuldades em avaliar o portfólio.

Quando indagados se consideraram que os alunos tiveram dificuldade de confeccionar o portfólio, um professor relatou que os alunos tiveram dificuldade em realizar o portfólio e não se sente motivado em empregar esse método de ensino-aprendizagem em outras disciplinas.

\section{DISCUSSÃO}

Segundo Krozeta (2008), a auto-avaliação, proporcionada pela construção do portfólio de ensino, pode ser utilizada como um dos instrumentos de aprendizagem e conseqüentemente mudança na formação profissional. Assim, é possível perceber que o elevado grau de aceitação do portfólio se dá pela promoção da auto-estima, da motivação, do exercício da autonomia, da responsabilidade e do compromisso do aluno diante de seus dados que essa auto-avaliação proporciona.

Entretanto, a maioria dos alunos questionados afirmou que teve dificuldades em confeccionar o Portfólio. Essa dificuldade está relacionada ao fato dos estudantes estarem predispostos a aulas expositivas que, segundo Lemos (2005), são apontadas como preferida pelos mesmos, que acham a posição de ouvinte mais confortável.

$\mathrm{O}$ antigo modelo pedagógico era centralizado na figura do professor; por conseqüência, a interferência criativa e crítica dos alunos, e até mesmo dos professores, era limitada (Freitas, 2009). Essa problemática é compreensível quando analisamos o modelo educacional presente na maioria das universidades brasileiras, modelo este ambientado em aulas expositivas e sem a participação ativa dos estudantes. $\mathrm{O}$ Portfólio pode preencher essa lacuna, a partir de mudanças nas metodologias de ensino, permitindo melhorias no desempenho acadêmico dos alunos e professores, estimulando o processo de educação 
permanente por meio de seminários e oficinas de capacitação. Essa proposta tem sido permanentemente encorajada pelo Projeto Pró-Saúde.

Outras dificuldades apontadas pelos estudantes tais como, a pesquisa de artigos e capacidade de síntese podem ser explicadas como reflexo da "educação bancária" recebida ao longo da vida em que o professor é o detentor do saber e o aluno é considerado uma tabula rasa, sendo o conhecimento transmitido verticalmente e sem estímulo à outras fontes de pesquisa. Percebeu-se que a pesquisa de artigos é uma dificuldade que os estudantes enfrentam no início de sua vida acadêmica, mas com o emprego do ambiente virtual de aprendizagem e familiarização dos estudantes com as ferramentas da internet, essa dificuldade tem sido superada; Além disso, os alunos têm a oportunidade de exercitar sua capacidade de comunicação escrita e se tornarem sujeitos ativos no processo de aprendizagem.

Ressalta-se a importância do estímulo à pesquisa e a capacidade de escrever e analisar o material investigado que é proporcionado na confecção do portfólio porque são características necessárias ao estudante para a realização do Trabalho de Conclusão do Curso (TCC).

O ambiente virtual de aprendizagem, o SOLAR, tem se mostrado muito bem aceito pelos alunos da UFC, quando contabilizados o número de acesso dos usuários. A aproximação do ambiente virtual de aprendizagem com novas metodologias de ensino, como o Portfólio, tem se mostrado de grande valia para facilitar o processo de ensino-aprendizagem e impulsionar a formação em Odontologia.

Entretanto, faz-se necessário descrever que o SOLAR, apresenta uma interfase em que é possível encontrar várias ferramentas de interação, como fórum, chat, e-mail e webconferência; ferramentas de apoio e publicação de material didático como bibliografia, material de apoio, espaço destinado ao repositório de aulas; ferramentas de portfólios individuais e de grupo, para compartilhamento de informações. Nessa perspectiva, é importante perceber que além do espaço destinado para abrigar o portfólio, o aluno dispõe de mecanismo de comunicação e interação com outros alunos e professores, permitindo a troca de saberes e experiências, além da opção de poder compartilhar sua produção escrita na área pública em que todos poderão acessar o portfólio individual. Acreditamos que essas facilidades proporcionadas pelo ambiente virtual também tenham motivado os alunos no processo de confecção do portfólio, pois permite a comunicação rápida e segura das informações entre os membros participantes.

A quase totalidade dos alunos considera o Portfólio melhor em termos de aprendizado que as provas tradicionais e diante disso se sentem motivados em realizá-lo em outras disciplinas.

O Portfólio pode ser usado como fonte de estudo, por conter as principais dúvidas e respostas, bem como resumos de pesquisas bibliográficas realizadas (Krozeta,2008), podendo portanto, auxiliar estudantes que não se sentem motivados a estudarem sozinho e realizaram as atividades propostas para a confecção do portfólio com facilidade.

Torres (2008), afirma que uma das principais dificuldades observadas pelos alunos analisados em seu estudo foi o pouco tempo dado para a confecção do Portfólio, entretanto no presente estudo a maioria dos alunos considerou que o tempo dado para a execução do portfólio foi suficiente, já que em média possuem três meses e meio para sua confecção a partir do início do semestre até seu término.

Há uma necessidade de mudanças na graduação do cirurgião-dentista para que seja possível formar os profissionais de forma generalista, humanista, crítica e reflexiva. Atualmente, nos cursos de graduação em Odontologia os currículos possuem uma enorme carga horária, não havendo tempo para estudo, o que resulta no repasse de conteúdos prontos e acabados, sem espaço para argumentação e dúvidas (Lazzarin, 2007).

O resultado apresentado em que $100 \%$ dos alunos afirmaram que a metodologia de ensino-aprendizagem utilizando o portfólio facilita o processo de aprendizagem, revela que a adoção de metodologias ativas devem ser implementadas no projeto político pedagógico do referido Curso, pois têm permitido uma maior autonomia dos estudantes, interação entre alunos e professores e estimulado a criatividade e à pesquisa.

Um pouco menos da metade dos alunos acredita não está preparado para estudar sozinho, portanto o professor tem papel fundamental no processo de ensino-aprendizagem agindo como um catalisador ou um promotor da aprendizagem e da troca de experiência.

O desafio do professor é abrir e não fechar o diálogo com seus alunos, entendendo a "Universidade" como um amplo território da multiplicidade e variedade de conhecimentos, para além de uma instituição da sociedade civilizatória. Nesse contexto, o portfólio permite o "feedback" do professor e o aluno se sente 
mais seguro e confiante para fazer as modificações sugeridas ou necessárias ao desenvolvimento do material produzido.

A prática do portfólio pode, ainda, proporcionar aos professores o trabalho processual, fazendo com que pratiquem o ensino de maneira significativa, isso explica o maior rendimento dos alunos e a aceitação dos professores a esse novo método de ensino-aprendizagem na odontologia, pois quando é usado o portfólio a aprendizagem tanto individual como do grupo é facilitada.

A avaliação dos alunos também se dá de forma processual e isso faz com que o portfólio seja melhor em termos de ensino-aprendizagem que as provas tradicionais.

Os professores no presente estudo não mostraram dificuldades em avaliar o portfólio, no entanto, entendemos que há constrições de tempo e pressões por instrumentos padronizados, mas em sua realidade cada professor pode encontrar possibilidades dentro de suas limitações e expectativas.

\section{CONClusões}

A utilização do portfólio é um instrumento pedagógico válido, aceito pelos alunos e pelos professores e que pode ser facilmente empregado no ensino odontológico.

Considera-se que os benefícios alcançados com o uso do portfólio na graduação são inegáveis, pois reflete o progresso de cada aluno na compreensão da realidade e de seu contexto de trabalho, na aquisição e organização dos conteúdos adquiridos e ao mesmo tempo, possibilita ao professor perceber os avanços e as transformações ocorridas durante a construção do conhecimento dos seus alunos ao longo das disciplinas ou módulos ministrados.

\section{ABSTRACT}

The portfolio as a facilitating strategy of the teaching-learning process for dentistry training. Suitability of teaching methods using the virtual environment for learning

The search for knowledge, creativity, and writing production are encouraged when a portfolio is used as a learning tool. This study aims to evaluate the portfolio as a facilitator of the teaching-learning process for dentistry training. A descriptive and cross-sectional survey was held in the second semester of 2010, in the Dentistry School at UFC. A questionnaire was applied to regularly enrolled academics in the disciplines of Scientific Methodology applied to Dentistry
I and Public Health II, totaling 60 students and three teachers of these disciplines. Data collection was performed by electronic questionnaires using a list of email addresses registered at a virtual learning site. For analysis purposes, the information obtained was organized into an Excel database and later analyzed by a statistics program, Epi-info version 3.5.1. The research was submitted for evaluation and was approved by the Ethics Committee in Research, protocol 157/10. Analyzing the students questionnaires, $100 \%$ assessed the portfolio as an excellent or good evaluation method; $98.3 \%$ of these said that the portfolio was better than traditional tests, when the focus is on learning; and $100 \%$ of the students declared that the methodology of teaching and learning using the portfolio facilitates the learning process. All the professors believe that student efficiency is greatest when the portfolio is used and that it facilitates learning. It was concluded that the portfolio is a worthy education tool that is well accepted by students and that can be used in dental education.

\section{DESCRIPTORS}

Teaching. Education, Dental. Educational Measurement. -

\section{REFERÊNCIAS BIBLIOGRÁFICAS}

1. Albuquerque, S.H., Nogueira, C.B. O uso de portifólio como método avaliativo em disciplinas clínicas do curso de odontologia da Universidade de Fortaleza. In: $43^{\text {a }}$ Reunião da Associação Brasileira de Ensino Odontológico, 2008, Porto Alegre. Rev. ABENO. São Paulo: ABENO, 2008. v.8. p.31

2. Alvarenga,G.M.Portfólio:o que é e a que serve?.Revista Olho Mágico. vol.8, n. ${ }^{\circ}$ 1, p.19-21. Londrina. 2001

3. Alves, L. P. Portfólios como instrumentos de avaliação dos processos de ensinagem. In:_Anatasiou,L.G.C., Alves, L. P. Processo de ensinagem na Universidade: pressupostos para as estratégias de trabalho em aula. 6.ed-Joinville,SC:UNIVILLE, 2006, p.1001-119.

4. Bin-Junior O, Tomita N. Percepções sobre o processo ensinoaprendizagem em odontologia: uso de portfólio. In: $43^{\mathrm{a}}$ Reunião da Associação Brasileira de Ensino Odontológico, 2008, Porto Alegre. Rev. ABENO. São Paulo: ABENO, 2008. v.8. p.30

5. Cunha.F.S., Silva,A.L., Larentis,N.L., Fontanela,V.R.C., Nevado,R.A. Proposta de uma nova abordagem pedagógica para a Disciplina de Informática aplicada à Odontologia. Revista da ABENO. v. 5, n. 2, julho/dezembro - 2005.

6. Dantas da Silva, C.M.S.L.M, Tanji S. O portfólio reflexivo: pareceres dos estudantes de enfermagem. Revista Iberoamericana de Educación. n. 46, p.6 - 10, Julio, 2008.

7. Ferreira, M.C.I., e Bueno, A.L.G.(2005). "O portfólio como 
O portfólio como estratégia facilitadora do processo de ensino-aprendizagem para a formação em odontologia. Adequação de metodologias de ensino utilizando o ambiente virtual de aprendizagem • Frota MMA, Menezes LMB, Alencar CH, Jorge LS, Almeida MEL

avaliação na educação superior: Uma experiência de sucesso em um curso de pedagogia", em Santos, C.R.(Org.): Avaliação Educacional. São Paulo: Editora AVERCAMP.

8. Freitas, V.P., Carvalho, R.B., Gomes,M.J., Figueiredo,M.C., Faustino-Silva,D.D. Mudança no processo ensino-aprendizagem nos cursos de graduação em odontologia com utilização de metodologias ativas de ensino e aprendizagem. RFO, v. 14, n. 2, p. 163-167, maio/agosto 2009.

9. Hernández, F. Cultura Visual. Mudança educativa e projeto de trabalho. Porto Alegre: Artmed; 2000. 262p.

10. Krozeta,K., Meier.M.J., Danski,M.R. A auto-avaliação: uma possibilidade de mudança na formação profissional. Cogitare Enferm 13(4):612-5, Out/Dez. 2008.

11. Lazzarin,H.C., Nakama,L. e Cordoni Júnior,L. O papel do professor na percepção dos alunos de Odontologia. Saúde e Sociedade v.16, n.1, p.90-101, jan-abr 2007.

12. Tanji S., Danta da Silva, C.M.S.L.M. As potencialidades e fragilidades do portfólio reflexivo na visão dos estudantes de enfer- magem. Rev. Enferm. UERJ, Rio de Janeiro, v. 16, n.3, p. 392-8, jul/set. 2008. Disponível em: < http://www.bvsintegralidade. icict.fiocruz.br/lildbi/docsonline/1/6/161-v16n3a16. pdf > Acesso em: 03/06/2010.

13. Torres, S.C.G. Portfólio como instrumento de aprendizagem e suas implicações para a prática pedagógica reflexiva. Rev. Diálogo Educ., Curitiba, v.8, n.24, p.549-561, maio/ago. 2008.

14. Vieira, V.M.O.Portfólio: uma proposta de avaliação como reconstrução do processo de aprendizagem. Psicologia Escolar e Educacional, volume 6, Número 2, p.149-153.2002

15. Vilas Boas, B.M.F. O portfólio no curso de pedagogia: ampliando o diálogo entre professor e aluno. Educ. Soc. 2005. Jan-Abrl; 26(90):291-306.
Recebido em 07/07/2011

Aceito em 25/07/2011 